\title{
Research in the Agglomeration Level of Textile Industry in Yangtze River Delta Region of China
}

\author{
Hao Zhou* and Jiaona Wan \\ School of Economics, Wuhan Textile University, Wuhan, China \\ Corresponding Email: zhouhaoli@163.com
}

\begin{abstract}
This paper uses the EG index, which adjust accordingly to the textile industry data of Yangtze River Delta region of China to measure the level of textile industry agglomeration in Yangtze River Delta region of China from 2003 to 2014. The results show that the agglomeration level of textile industry in Yangtze River Delta region of China has experienced four stages: rapid growth, steady development, rapid decline and slow recovery. Through the analysis of the causes of the changes of agglomeration level namely EG index in each stage, this paper has found that the textile industry in Yangtze River Delta has several problems in industrial structure and enterprise development. Therefore, the corresponding recommendations were presented to promote the healthy development of the textile industry in Yangtze River Delta region.
\end{abstract}

\section{Introduction}

Yangtze River Delta has always been a highly developed area of China's textile industry, with its unique source of raw materials, low transport costs, low labor costs and other natural advantages, attracting a lot of capital invests into the textile industry. In its development process, the textile industry of Yangtze River Delta gradually formed industrial agglomeration. The idea of industrial agglomeration firstly appeared in Marshall's "external economic theory" and "internal economic theory" of "Principles of Economics ". Porter believes that industrial agglomeration is a form of spatial organization that creates competitive advantages in terms of efficiency, benefit and flexibility. It is generally accepted that industrial agglomeration refers to the agglomeration in a particular space of related firms in a particular industry and its associated supporting structures [1].

At present, the industrial agglomeration measurement methods used by domestic and foreign scholars mainly include industry concentration degree, location entropy, Herfindahl index, space Gini coefficient and EG index. Xiao Lei and Botang Han(2011) used the EG index to measure the industrial agglomeration level of Chinese manufacturing industry, and Get 2003-2007 industries' agglomeration level of Chinese manufacturing industry [2]. Chaoping Sun, Huiming Liu and Yong $\mathrm{Wu}$ (2015) used the two-dimensional namely economy and scale location entropy to measure the agglomeration level of textile industry in 26 regions of China in 2011 and 2013. It is found that China's textile industry agglomeration level is not complete a pattern that high in east and low in west [3]. Jing Hu, Luping Chen and Mi Zhou (2015) used the Herfindahl index and the spatial Gini coefficient to measure the agglomeration level of tourism industry in Hubei Province from 2005 to 2012, and compared the changes of tourism industrial agglomeration level before and after the opening of high-speed railway. On this basis, they analyzed the differential impact of highspeed railway on tourism industry and relevant industries [4].

In industrial agglomeration research field, it is clear that foreign scholars started earlier and has formed a mature theoretical system. Since the 90 s, domestic scholars have also been studying industrial agglomeration and combining with Chinese national conditions to output a large number of empirical research results. It is in this context, this paper uses the EG index which is suitable for measuring the agglomeration level of the textile industry to measure the textile industry agglomeration level in Yangtze River Delta region of China in 2003-2014, which stands on the sustainable development of the textile industry in Yangtze River Delta region of China and making reasonable suggestions. In addition, the scope of Yangtze River Delta region of China in this paper includes Shanghai, Jiangsu and Zhejiang provinces.

\section{Measurement of agglomeration level in textile industry}




\subsection{The measurement method of industrial agglomeration level}

At present, the industrial agglomeration measurement methods used by domestic and foreign scholars mainly include industry concentration degree, location entropy, Herfindahl index, space Gini coefficient and EG index. Considering the applicable conditions of the various measurement methods, this paper finally choose EG index to measure the agglomeration level of textile industry [5].

\subsubsection{Ellison - Glaeser index}

Ellison - Glaeser index referred to as "EG index", Ellison and Glaeser proposed the EG index which improved largely based on the space Gini coefficient $\mathrm{G}$ and Herfindahl index $\mathrm{H}$ to overcome the drawback that a large enterprise in a region may lead to a inflated $\mathrm{G}$ index in space Gini coefficient; It also avoids the uncertainty of existence of the positive correlation between Herfindahl index and industrial agglomeration level. The EG index is calculated as:

$$
\gamma=\frac{G-\left(1-\sum_{i} x_{i}^{2}\right) H}{\left(1-\sum_{i} x_{i}^{2}\right)(1-H)}
$$

Among them, $\mathrm{G}=\sum_{i}\left(s_{i}-x_{i}\right)^{2}, \mathrm{H}=\sum z_{j}, s_{i}$ is the ratio of employment of one industry in i region to employment of the industry in the whole nation; $x_{i}$ is the ratio of employment in i region to total employment in the whole nation; ${ }_{j}$ is the market share of one firm within one industry in $\mathrm{j}$ region [6].

\subsubsection{The adjustment of Ellison - Glaeser index}

Taking into account the availability of data, the Yangtze River Delta textile industry employment data is not available, so when calculating the space Gini coefficient namely G uses the enterprises' number of Textile Industry in Yangtze River Delta region and the whole nation to replace it. The adjusted G is:

$$
G^{\prime}=\sum_{i}\left(n_{i}-x_{i}\right)^{2}
$$

Where $n_{i}$ is the ratio of the enterprises' number of one industry in i region to the enterprises' number of the industry in the whole nation.

In addition, Herfindahl index $\mathrm{H}$ refers to the sum of square of market share of all enterprises within an industry in a region. Obviously, the market share of all enterprises within the textile industry in the Yangtze River Delta is not available, so the adjusted $\mathrm{H}$ is approximately calculated as the following formula:

$$
H^{\prime}=\sum_{j} \frac{1}{m_{j}} s_{j}^{2}
$$

Where $m_{j}$ is the enterprises' number within one industry in $\mathrm{j}$ region; $S_{j}$ is the ratio of the total assets of one industry in $\mathrm{j}$ region to the total assets of the industry in the whole nation [7].

The adjusted EG index is:

$$
\gamma^{\prime}=\frac{G^{\prime}-\left(1-\sum_{i} x_{i}^{2}\right) H^{\prime}}{\left(1-\sum_{i} x_{i}^{2}\right)\left(1-H^{\prime}\right)}
$$

\subsection{Data selection and measurement results}

Based on the adjusted EG index, the data selected in this paper is the number of textile enterprises, the total assets of the textile industry and the number of employees in the textile industry from 2003 to 2014 in Shanghai, Jiangsu, Zhejiang and the whole nation. Where the data of the number of textile enterprises and the total assets of the textile industry from 2003 to 2014 in Shanghai, Jiangsu, Zhejiang and the whole nation is derived from the State Council Development Research Center Information Network Database, while the data of the number of employees in the textile industry from 2003 to 2014 in Shanghai, Jiangsu, Zhejiang and the whole nation is derived from the National Bureau of Statistics and the Local (Shanghai, Jiangsu, Zhejiang)Bureau of Statistics. The measurement results of the textile industry agglomeration level of Yangtze River Delta region are shown in Table 1 and Figure 1(In order to more intuitively observe the changes of textile industry agglomeration level in 2003-2014 in Yangtze River Delta region, the Figure 1 is specially made for reference).

Table 1 and Figure 1show that the textile industry agglomeration level -EG index in Yangtze River Delta region was in a rapid growth stage from 2003 to 2005, with growth rates of 7.1\% and 24.2\% respectively. From 2005 to 2010 , the agglomeration level of the textile industry -EG index in Yangtze River Delta region was in a steady development stage .In addition to 2007 compared with 2006 increased by $7.8 \%$, the EG index rose less than $3 \%$ in the rest of the years. Furthermore, the EG index was always between 0.8 and 0.9 in this stage. In 2010-2011, the agglomeration level of the textile industry -EG index in Yangtze River Delta region was in a sharp decline stage and it decreased by $32.9 \%$ 
while still greater than 0.05. In 2011-2014, the agglomeration level of the textile industry -EG index in Yangtze River Delta region was in a slow recovery stage and increased as the time went on, with the growth rates of $2.1 \%, 1.2 \%$ and $4.6 \%$ respectively.

Table 1. 2003-2014 Textile industry agglomeration level-EG index in the Yangtze River Delta.

\begin{tabular}{|c|c|c|c|}
\hline year & $\mathrm{H}^{\prime}$ & $\mathrm{G}^{\prime}$ & EG index \\
\hline 2003 & $2.78774 \mathrm{E}-05$ & 0.06168604 & 0.061986165 \\
\hline 2004 & $2.59456 \mathrm{E}-05$ & 0.066074332 & 0.066399493 \\
\hline 2005 & $2.05806 \mathrm{E}-05$ & 0.082023463 & 0.082444926 \\
\hline 2006 & $1.894 \mathrm{E}-05$ & 0.08031534 & 0.080736289 \\
\hline 2007 & $1.69384 \mathrm{E}-05$ & 0.086544721 & 0.087024817 \\
\hline 2008 & $1.63908 \mathrm{E}-05$ & 0.084887202 & 0.085393906 \\
\hline 2009 & $1.4579 \mathrm{E}-05$ & 0.085023886 & 0.085551865 \\
\hline 2010 & $1.42133 \mathrm{E}-05$ & 0.087422193 & 0.087971553 \\
\hline 2011 & $2.18174 \mathrm{E}-05$ & 0.058698918 & 0.059056311 \\
\hline 2012 & $2.22723 \mathrm{E}-05$ & 0.059907022 & 0.060270608 \\
\hline 2013 & $2.02819 \mathrm{E}-05$ & 0.060595597 & 0.060970614 \\
\hline 2014 & $1.8255 \mathrm{E}-05$ & 0.06339555 & 0.063788203 \\
\hline
\end{tabular}

Source: the State Council Development Research Center Information Network Database, the National Bureau of Statistics and the Local (Shanghai, Jiangsu, Zhejiang) Bureau of Statistics.

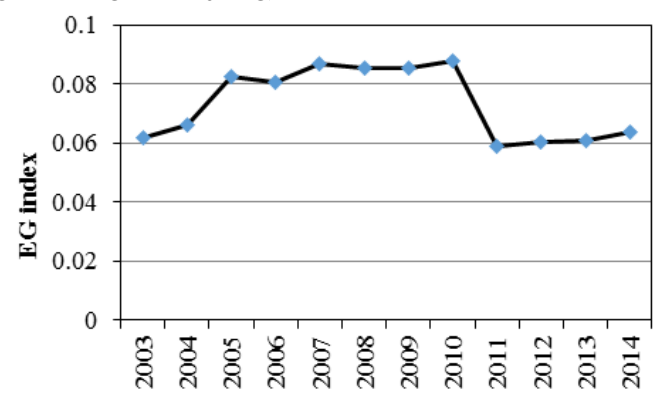

Fig. 1. 2003-2014 Textile industry agglomeration level-EG index in the Yangtze River Delta.

\section{Analysis of the changes of textile industry agglomeration level in different stages}

The Yangtze River Delta region is always the more developed areas of Chinese textile industry. It is generally acknowledged that if industrial agglomeration level $>0.05$, the industry is considered to be highly agglomerated in the region. The data shows that the textile industry agglomeration level-EG index in Yangtze River Delta were all greater than 0.05 in 2003-2014, which also squares with the current situation of the textile industry in Yangtze River Delta region. According to the measurement results of industrial agglomeration, the change of textile industry agglomeration level in Chinese Yangtze River Delta can be divided into four stages.

\subsection{Rapid growth stage}

From 2003 to 2005, the textile industry in Yangtze River Delta region was in the agglomeration efficiency increasing stage, in another word, the higher the agglomeration level of textile industry in the region, the more output a single textile enterprises will obtain from a certain proportion of the capital input. This is due to the textile enterprises in 
Yangtze River Delta region had a cost advantage at the stage: sources of abundant and inexpensive raw materials, less transportation costs formed by perfect transport infrastructure and its inherent geographical advantage and lower labor costs. While, the cost advantage led to the profit level of textile industry in the Yangtze River Delta was higher than industrial average profit level, which attracted a lot of capital into the textile industry, expanded the industrial scale, and in return the agglomeration level of textile industry -EG index was increasing.

\subsection{Steady development stage}

In 2005-2010, the agglomeration level of textile industry in Yangtze River Delta region had been maintained at a high level of 0.08-0.09. At this moment the textile industry in Yangtze River Delta region was in the agglomeration efficiency constant stage and the market was saturated, and the capital input couldn't bring ultra - proportional income. Capital flowed in and out but had been maintained at a equalizing level and the scale of the industry was also nearly unchanged, so the agglomeration level of textile industry maintained at around 0.08 during this period.

\subsection{Sharp decline stage}

Causing the agglomeration level of textile industry in Yangtze River Delta region dropped significantly in 2011, mainly due to a large number of textile enterprises closed down. The reasons are as follows: on the one hand, the decline of international competitiveness of textile enterprises. The majority of textile enterprises did not pay attention to innovation and were committed to producing some low value-added low-end textiles; On the other hand, the increase in labor costs. The labor costs of some Southeast Asian countries (Such as India, Laos, Cambodia and etc.) is cheaper than our country, China has gradually lost its labor cost advantage; In addition, the land resources in Yangtze River Delta region is increasingly scarce, which makes the cost of fixed assets is also increasing. These unfavorable factors make the profits of the textile enterprises in the region greatly shrunk, which led to many small and medium textile enterprises can't make ends meet and one after another closed down.

\subsection{Slow recovery stage}

In 2011-2014, the agglomeration level of textile industry -EG index in Yangtze River Delta region was slowly increased year by year, and had been maintained at around 0.06. After the closure of the tide in 2011, capital greatly flowed out of the textile industry, and the market was again in the agglomeration efficiency increasing stage. Furthermore, the textile industry in Yangtze River Delta region actively participated in technological innovation, industrial upgrading, improving the industrial chain and enhancing the international competitiveness in this period.

\section{Conclusions}

By using the EG index to measure the agglomeration level of textile industry in Yangtze River Delta region of China from 2003 to 2014, this paper has found that the agglomeration level of textile industry in Yangtze River Delta region of China has experienced four stages: rapid growth stage, steady development stage, sharp decline stage and slow recovery stage. In this paper, the following suggestions are proposed:

Firstly, since the agglomeration level of textile industry in Yangtze River Delta region has been at a high level, namely the market has been saturated and the cost (such as land resource costs and labor costs) increased year by year, the textile industry in Yangtze River Delta region can be considered to transfer to central and western regions whose agglomeration level of textile industry is lower.

Secondly, for the textile enterprises in the Yangtze River Delta region, it is imminent to improve the enterprise's innovation consciousness, complete the upgrading of machinery and equipment and improve the core competitiveness of enterprises.

Finally, for the textile industry in the Yangtze River Delta region, with the increasing international competitiveness, it should continue to adhere to in-depth promotion of transformation and upgrading and constantly improve the industrial chain to maintain steady growth of the textile industry.

\section{Acknowledgement}

The research was supported by Hubei Provincial Department of Education Science Research Major Project under Grant No. 14 zd022.

\section{References}

1. Wei Zou, Modern economy,3(2007).

2. Xiao Lou, Botang Han, Science and Technology Progress Countermeasure, 8(2012).

3. Chaoping Sun, Huiming Liu, Yong Wu, Industrial Technology \& Economy, 12(2015). 
4. Jing Hu, Luping Chen, Mi Zhou, Journal of Chongqing traffic University, 5(2015).

5. Jian Hu, Chunshi Dong, Statistics and Information Forum, 1(2013).

6. Ellison G, Glaeser E. JPE, 105,5(1997).

7. Hongjiao Yang, Linyan Sun, Anbo Wu, China Industrial Economy, 4(2008). 